\title{
Pitfalls in clinical diagnosis and treatment of infectious meningitis in China
}

\author{
Jia-Tang Zhang \\ Department of Neurology, Chinese PLA General Hospital, Beijing 100853, China.
}

\section{INTRODUCTION}

Infectious disease of the central nervous system (CNS), such as meningitis, is one of the most important categories of neurological conditions. Such diseases are challenging in terms of diagnosis, treatment, and prognosis. Meningitis occurs most often in young- and middle-aged patients, and the rate of misdiagnosis, especially during the early stages of the disease, is high. Correct diagnosis and treatment can save lives, but many factors, such as difficulty in medications crossing the blood-brain barrier (BBB) can cause difficulty in treatment.

\section{ANALYSIS OF THE MISDIAGNOSIS RATE OF INFECTIOUS MENINGITIS}

There are several reasons for the high rate of misdiagnosis in meningitis: (1) the development of this clinical sub-specialty is relatively recent. The professional setting and staffing for research into infectious CNS diseases fall behind those for research into cerebrovascular, demyelinating, neuromuscular, degenerative, and genetic diseases. At present, only a few hospitals in China, such as in Beijing, Shanghai, Xi'an, Shijiazhuang, and Yinchuan, have infection and cerebrospinal fluid cytology (CSFC) as a professional sub-specialty. (2) The content of current textbooks is out of date. It lacks data from large, double-blind, multicenter, case-control studies,

\begin{tabular}{|l|l|}
\hline \multicolumn{2}{|c|}{ Access this article online } \\
\hline Quick Response Code: & \\
\hline & Website: \\
\hline & www.nnjournal.net \\
\cline { 2 - 3 } & DOI: \\
\hline
\end{tabular}

as well as basic research data. The data on meningitis in current textbooks are about 40-50 years old, and some are from foreign studies, whereas the chapters on cerebrovascular disease are updated every 5-10 years. (3) The clinical manifestations of meningitis can be atypical. Meningitis has shown the greatest change in clinical manifestations over time compared with other nervous system diseases. "Atypical clinical manifestations" may, in fact, be the current "typical" features, but are different from the manifestations seen 50 years ago. The 50-year fight between the meningitis pathogen and the human immune system, the natural variation of the pathogenic organisms, the misuse of antibiotics and immune suppressants, and the prevalence of drug addiction and AIDS have all produced changes in the clinical manifestations of meningitis. (4) Obtaining samples of the pathogen is difficult. Taking a biopsy from the mater has technical limitations, and it may be difficult for the patient and family to accept. The positivity rate for pathogens in CSF is very low, except for Cryptococcus neoformans, which can be $99 \%$ in most references. ${ }^{[1,2]}$ The textbooks state that the positivity rate for Mycobacterium tuberculosis by smear and culture of bacteria from CSF can be as high as $30 \%-40 \%$, but clinical reports from most hospitals show a positive rate of below $10 \%$. Of 167 patients with tubercular meningitis who were assessed during the period 1990-2010 in our hospital, only one had a positive result for $M$. tuberculosis by bacterial smear and culture from CSF samples. ${ }^{[3]}$ Using the new acid-fast stain method of The Fourth Military Medical University, the positivity rate of CSF smear can be above $90 \%$, enabling early diagnosis of tubercular meningitis. ${ }^{[4]}$ Identifying the pathogens underlying cases of viral meningitis, weakly pathogenic bacterial meningitis, and parasitic meningitis is also difficult. For these reasons, the misdiagnosis rate in early meningitis is very high.

Corresponding Author: Dr. Jia-Tang Zhang, Department of Neurology, Chinese PLA General Hospital, No. 28 Fuxing Road, Haidian, Beijing 100853, China. E-mail: edwin-zhang@263.net 


\section{DIFFICULTIES IN DIAGNOSIS AND TREATMENT OF INFECTIOUS MENINGITIS}

The BBB protects the brain tissue, but is also the greatest obstacle to treatment of infectious meningitis. The focus is often on the effective permeation rate of treatment drugs across the BBB, instead of the sensitivity of the drug, which can influence the efficacy of treatment. ${ }^{[5]}$

High doses and a long treatment course are needed for therapy of infectious meningitis. For example, an intensive course of treatment for tubercular meningitis requires a dose of isoniazid of $15 \mathrm{mg} / \mathrm{kg}$ per day, whereas the general dose in instruction is $0.6 \mathrm{~g} /$ day. The treatment course for intracranial tuberculosis is double that for extracranial tuberculosis, that is, 4-6 months of intensive treatment and 18-24 months for the whole course. ${ }^{[6]}$ Such doses and treatment courses pose challenges for both doctors and patients.

Because of the problems of pathogen isolation and difficulty in permeating the BBB, doctors need to perform experimental therapies and choose drugs that can effectively cross the BBB. That means doctors have to break the usage principle of antibiotics or the medical insurance regulations. This is also a great challenge.

From the three points above, we can see that the risk of treatment failure in infectious meningitis is higher than in other infectious diseases. Doctors are extremely concerned about the risk in specific countries and regions (tense physician - patient relationship) or of legal action.

\section{DIAGNOSIS AND TREATIMENT OF MENINGITIS}

Differential diagnosis of infectious and noninfectious meningitis

A patient presenting with fever, headache, nausea, emesis, meningeal irritation, and abnormal CSF findings (high pressure, increased white cell count, and decreased glucose and chloride levels) is easily misdiagnosed as having meningitis. However, it is necessary to exclude noninfectious causes of meningitis such as chemicals, connective tissue diseases, and tumors. A patient with chemical meningitis usually has a clear history of intrathecal medicine injection such as cytarabine, methotrexate, or analgesics. Because chemical meningitis often occurs during a period of hospitalization or in patients with a clear history of using specific medicines, it is easier to exclude. Connective tissue disease-related meningitis is often ignored. In such cases, we need to clarify if there is a medical history of systemic lupus erythematosus, sarcoidosis, or rheumatoid arthritis; order the appropriate laboratory investigations; and request a rheumatology consultation. Tumor-related meningitis (immunity meningitis or cancerous meningeal disease) can present with fever or other symptoms of meningitis. Detection of tumor markers in blood and CSF, cytology testing of CSF, and scans (computed tomography, magnetic resonance imaging [MRI], and positron emission tomography) can be helpful in the differential diagnosis.

Differential diagnosis of possible infectious meningitis pathogens

Pathogens causing infectious meningitis include bacteria, fungi, and viruses. It is important to distinguish the species of pathogens with no result of CSF smear. Purulent meningitis is easier to identify by observing the CSF appearance, CSF cell number, and the percentage of multinucleate cells.

Viral, tuberculous, and C. neoformans meningitis are more difficult to distinguish. The disease course for tuberculous and C. neoformans meningitis is over 6 weeks, and may be as long as several months, but that for viral meningitis is often less than 3 weeks. The body temperature of a patient with viral or C. neoformans meningitis can be over $39^{\circ} \mathrm{C}$, but a patient with tuberculous meningitis often has fever in the afternoon and the body temperature is below $39^{\circ} \mathrm{C}$.

With regard to CSF examination, the differences between the various meningitis types are as follows: (1) pressure: in C. neoformans meningitis, pressure is above $300 \mathrm{mmH}_{2} \mathrm{O}$; in tuberculous meningitis, it is more often between 250 and $280 \mathrm{mmH}_{2} \mathrm{O}$ (rarely above $300 \mathrm{mmH}_{2} \mathrm{O}$ unless there is meninges adhesion); and in viral meningitis, it is normal or a little higher, rarely above $250 \mathrm{mmH}_{2} \mathrm{O}^{[7]}$ (2) Glucose and chloride levels: in tuberculous meningitis, these are both decreased or at least glucose is decreased, sometimes below $1.0 \mathrm{mmol} / \mathrm{L}$; in viral and C. neoformans meningitis, glucose is decreased or normal, often between 2.0 and $2.8 \mathrm{mmol} / \mathrm{L}$, while chloride is generally normal, or if decreased, is often between 110 and $118 \mathrm{mmol} / \mathrm{L}$. (3) Protein levels: in tuberculous meningitis, protein is obviously increased at between 1.0 and $2.0 \mathrm{~g} / \mathrm{L}{ }^{[8]}$ and may be over $10 \mathrm{~g} / \mathrm{L}$, but in viral and C. neoformans meningitis, it is rarely more than $1.0 \mathrm{~g} / \mathrm{L}$.

Using MRI with enhancement, we can see that the strengthened signals in the meninges are strongest for 
tuberculous meningitis, and are sometimes accompanied by ring enhancement of tuberculoma. ${ }^{[9]}$ These signals are weakest for viral meningitis and may sometimes be absent.

How to determine the diagnosis and treatment strategy without identifying the pathogen?

It is difficult to determine the diagnosis and treatment strategy without having pathogen identification. On the basis of that stated above, experimental therapy can be carried out for 2-3 weeks if we have propensity diagnosis, and then the subsequent strategy can be determined based on the effect of treatment. If there is no tendency for diagnosis, my personal experience is as follows.

Step 1: we treat the condition as viral meningitis for 2-3 weeks. This treatment can continue if there is a positive effect on the clinical, CSF, or imaging findings; otherwise, we go on to the next step. Step 2: we treat it as tuberculous meningitis for 2-3 weeks. This treatment can continue if there is a positive effect on the clinical, CSF, or imaging findings; otherwise, we go on to the next step. Step 3: we treat it as $C$. neoformans meningitis for $2-3$ weeks, and then assess the effect.

During every treatment step, efforts must continue to identify the pathogen and then re-diagnose. If the pathogen is identified, targeted treatment can commence; otherwise, we can only perform experimental therapy based on the clinical, CSF, or imaging findings.

\section{REFERENCES}

1. Adam P, Sobek O, Dolezil D, Lodin Z, Kasík J, Hajduková L, Cihelková S, Svatonová J, Hybel'ová M, Adam D, Melezinková $\mathrm{V}$. Cryptococcal meningitis - a follow-up study of a serious clinical entity: quick cytological and microbiological diagnostics using a special staining procedure in cerebrospinal fluid specimens. Folia Microbiol (Praha) 2009;54:567-8.

2. Fan XH, Feng GD, Yang YN, Dai W, Zhao G. Diagnostic value of May-Grunwald-Giemsa staining of cerebrospinal fluid in patients with cryptococcal meningitis. $J$ Int Neurol Neurosurg 2013;40:220-2.

3. Hu J, Zhang JT, Lang SY, Pu CQ. Analysis of cerebrospinal fluid from 167 cases of tuberculous meningitis. Med J Chin Peoples Liberation Army 2010;35:580-3.

4. Chen P, Shi M, Feng GD, Liu JY, Wang BJ, Shi XD, Ma L, Liu XD, Yang YN, Dai W, Liu TT, He Y, Li JG, Hao XK, Zhao G. A highly efficient Ziehl-Neelsen stain: identifying de novo intracellular Mycobacterium tuberculosis and improving detection of extracellular M. tuberculosis in cerebrospinal fluid. J Clin Microbiol 2012;50:1166-70.

5. Pardridge WM. Drug targeting to the brain. Pharm Res 2007;24:1733-44.

6. Prasad K, Sahu JK. Duration of anti-tubercular treatment in tuberculous meningitis: challenges and opportunity. Neurol India 2010;58:723-6.

7. Hu J, Zhang JT, Lang SY, Pu CQ. Clinical analysis of 47 misdiagnosed cases of atypical tuberculous meningitis. Nan Fang Yi Ke Da Xue Xue Bao 2011;31:175-9. (in Chinese)

8. Wang JT, Hung CC, Sheng WH, Wang JY, Chang SC, Luh KT. Prognosis of tuberculous meningitis in adults in the era of modern antituberculous chemotherapy. J Microbiol Immunol Infect 2002;35:215-22.

9. Feng WJ, Zhang Y, Liu X, Liu B. The imaging characteristic of CT of tuherculous meningitis. Mod Med Image 2009;18:207-10

Cite this article as: Zhang JT. Pitfalls in clinical diagnosis and treatment of infectious meningitis in China. Neuroimmunol Neuroinflammation 2014;1(1):3-5

Source of Support: Nil. Conflict of Interest: No.

Received: 03-05-2014; Accepted: 29-05-2014 